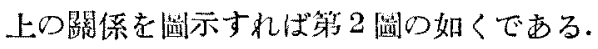

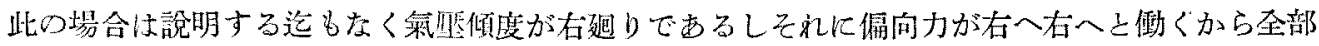
風は右趣りとなるのは蠋然でする.

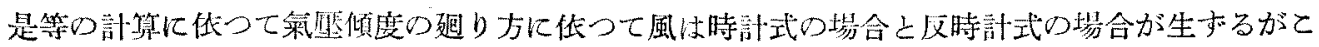

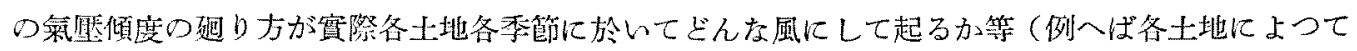
山脈の走向の相造, 海陸分布の相造, 其の他の原因で太陽上り受ける日射が時間之共にどういふ具

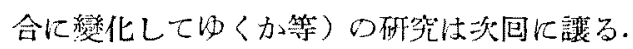

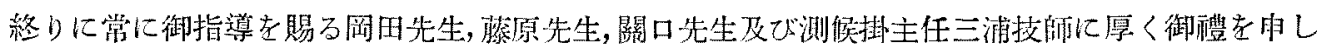
述べす.

地 球 電 磁 場に 就 で

山本主夫

On the Earth's Electromagnetic Field.

By N. Yamamoto.

\begin{abstract}
I have attempted to clear the nature of the earth's electromagnetic field by means of electrodynamics. It is proved that the conductivity of the earth lessens the storage of electric energy near the surface when there is no accumulation of charge.
\end{abstract}

\begin{tabular}{|c|c|c|c|}
\hline \multicolumn{4}{|c|}{ 記 跕の話明 } \\
\hline c & 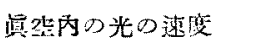 & $\mathrm{E}$ & 電場の强き (esu) \\
\hline $\mathrm{H}$ & 磁場の强さ & I & 僸尊電流の强さ (esu) \\
\hline & 莹閒需荷の密度 (esu) & $\kappa$ & 雪氣傳澊度 (esu) \\
\hline & 誘䉓率 & $\mu$ & 誘磁率 \\
\hline & ベクトルポテンシアル & $\phi$ & スケラーポテンシアル \\
\hline
\end{tabular}

\title{
1. 電流と磁場及び電場（遠達作用論）
}

電氣現像は策質の運動に隨件するもの之假定すれば微分型の電磁式は

$$
\begin{gathered}
\nabla \times H=\frac{1}{c}(\dot{D}+4 \pi I+q \nabla \cdot D+\nabla \times[D, q]) \\
\nabla \times E=-\frac{1}{c}(\dot{B}+\nabla \times[B, q]) \ldots \ldots \ldots \ldots
\end{gathered}
$$

(1) 巾央氣象䇺整報. 
地球に關した問題では相對的の蓮動をする導體はないから $\nabla \times[B, q]$ にる起電力仗樌分型に直

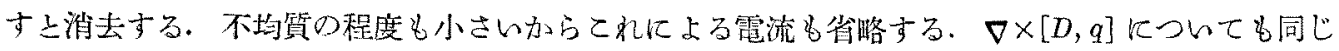
ことが言へる. 又 $q \nabla \cdot D$ は $\nabla \cdot D$ が小さいから省略して (1)，(2) 式で $q$ の付いた項驻全部考へな いととにする.

媒質を均質としてポテンシアル函數を使へば

$$
\begin{gathered}
E=-\frac{\mu}{c} \dot{A}-\nabla \phi \\
H=\nabla \times A \cdots
\end{gathered}
$$

但し

$$
\begin{aligned}
A & =\frac{1}{c} \int \frac{[I]}{r} d \tau \ldots \ldots . \\
\phi & =\frac{1}{\varepsilon} \int \frac{[\rho]}{r} d \tau \ldots \ldots \ldots \\
\frac{\varepsilon}{c} \dot{\phi}+\nabla \cdot A=0 & \text { 或Uは } \frac{\partial \rho}{\partial t}=-\nabla \cdot I
\end{aligned}
$$

retardation bracket [ ] は $v=\frac{e}{\sqrt{\varepsilon \mu}}$ につんて行ふ.

$\kappa \neq 0$ なれば $\rho=0$ となりグリーンの定理 $\phi=\int \frac{[\rho]}{r} d \tau+\frac{1}{4 \pi} \int n \cdot\left(\frac{\nabla[\phi]}{r}-[\phi] \nabla \frac{1}{r}\right) d S$ から $\phi$ は實際には表面電荷のみで求められる。但しッは外向法線の單位ベクトルである.

(3)より $E_{z}$ は $\dot{I}_{z}$ によつて求められるが $I_{z}$ の實测がないから實際の現像に觸れるこよは出來

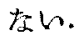

\section{2. 電場 と磁場（媒達作用論）}

到る處 $\nabla \cdot E=0$ ○電信方程式は

$$
\nabla^{2} E-\frac{\varepsilon \mu \ddot{E}}{c^{2}}-\frac{4 \pi \mu \kappa}{c^{2}} E=0
$$

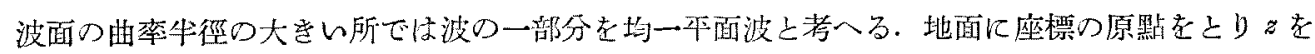
下方にとる.波は單一周期を持つてるるとし $z$ の正の方向に傳播するのとす。

波面では $E_{z}=H_{z}=0, E \cdot H=0$, 故に $E_{x}, H_{y}$ のみを考へるととにする.

$$
\begin{aligned}
& \kappa=0 \text { のときは } E_{x}=E_{0} e^{i n\left(t-\frac{z}{v}\right)}
\end{aligned}
$$

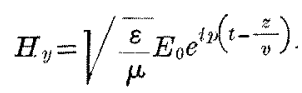

$$
\begin{aligned}
& \frac{\kappa}{p} \rightarrow 0 \text { のとをは } \\
& E_{s}=E_{0} e^{-\frac{9 \pi_{\kappa}}{c \sqrt{\frac{\varepsilon}{\mu}}} \tau i p\left(t-\frac{z}{v}\right)} \\
& H_{y}=\sqrt{\frac{\varepsilon}{\mu}+\left(\frac{2 \pi \kappa}{p \sqrt{\varepsilon \mu}}\right)^{z}} E_{0} e^{-i \tan ^{-1} \frac{2 \pi \kappa}{p \varepsilon}} e^{-\frac{2 \pi \kappa}{c \sqrt{\frac{\varepsilon}{\mu}} z} e^{1 p\left(t-\frac{z}{v}\right)}}
\end{aligned}
$$




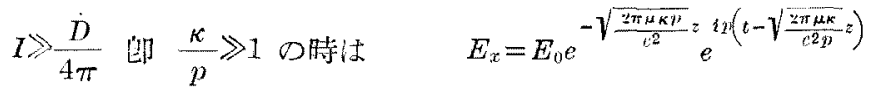

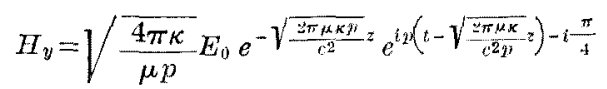

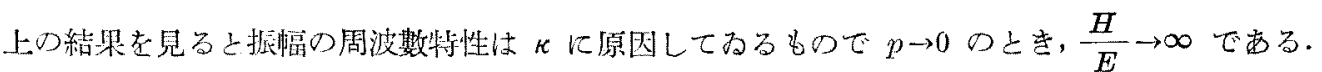

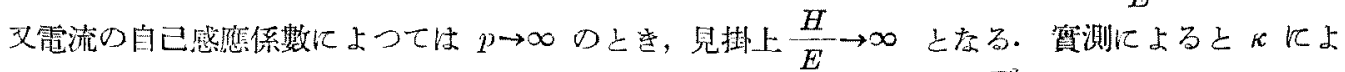

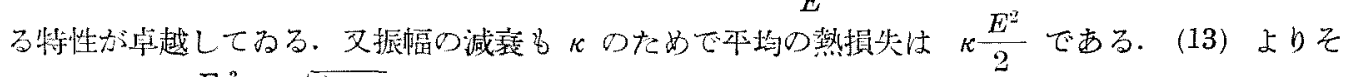

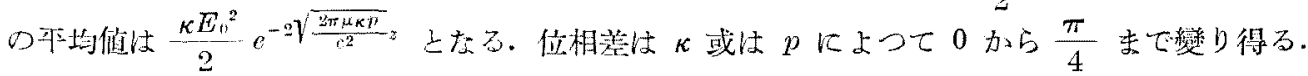

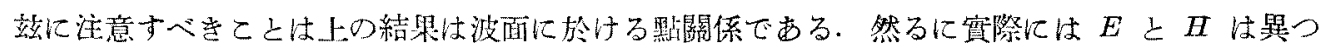

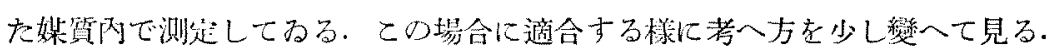

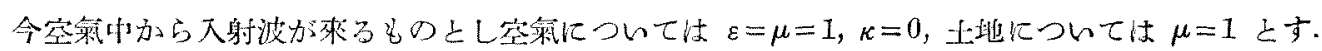
入射波の波形しして $E_{x}=E_{0} \cos p\left(t-\frac{z}{c}\right)$ 在撰べば $\kappa=0$ の上要は

又彩波 $E_{x}=E_{0} \cos p\left(t-\frac{z}{c}\right), \quad H_{y}=E_{00} \cos p\left(t-\frac{z}{c}\right)$

$$
\begin{array}{ll}
\text { 反射波 } & E_{x}{ }^{\prime}=-\frac{\sqrt{\varepsilon}-1}{\sqrt{\varepsilon}+1} E_{0} \cos p\left(t+\frac{z}{v}\right) \\
\text { 屈折波 } E_{x}{ }^{\prime \prime}=\frac{2}{\sqrt{\varepsilon}+1} E_{0} \cos p\left(t-\frac{z}{v}\right)
\end{array}
$$

即ち殆んど總て屈折波さなつて反射波は小さい。

$\frac{\kappa}{p} \gg 1$ のとき

反射波 $\quad E_{x}^{\prime}=-(1-\delta) E_{0} \cos \left[p\left(t+\frac{z}{c}\right)-\delta\right], \quad H_{y}^{\prime}=(1-\delta) E_{0} \cos \left[p\left(t+\frac{z}{c}\right)-\delta\right]$

屈折波

$$
\begin{aligned}
& E_{x}^{\prime \prime}=\sqrt{\frac{p}{\pi \kappa}} E_{0} e^{-\sqrt{\frac{\pi \kappa^{2}}{c^{2}} z}} \cos \left[p\left(t-\sqrt{\frac{\overline{2 \pi \kappa}}{c^{2} p} z}\right)+\frac{\pi}{4}\right]
\end{aligned}
$$

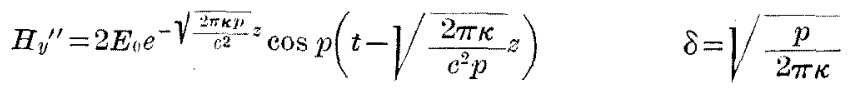

$\kappa=\infty の と は$

$$
\text { 反身波 } E_{x}^{\prime}=-E_{0} \cos p\left(t+\frac{z}{c}\right) \quad H_{y}{ }^{\prime}=E_{0} \cos p\left(t+\frac{z}{c}\right)
$$

ての二つの波は合成されて停立波となる。

$$
E_{x}=2 E_{0} \sin \frac{p z}{c} \sin p t \quad H_{y}=2 E_{0} \cos \frac{p z}{c} \cos p t
$$

$H_{y}$ の第一D節照は $\frac{\lambda}{4} \gg 10^{5} \mathrm{~km}$ の所にある.

$\frac{\kappa}{p} \gg 1$ 上き地面に於けるエネルギーの平均の流れは 
大射波 $\frac{E_{0}{ }^{2}}{2}$ 反射波 $\frac{E_{0}{ }^{2}(1-\delta)^{2}}{2}$ 届折波 $E_{0}{ }^{2} \delta$

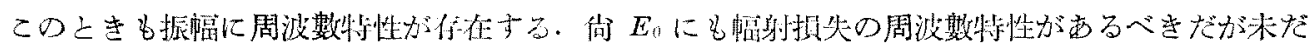

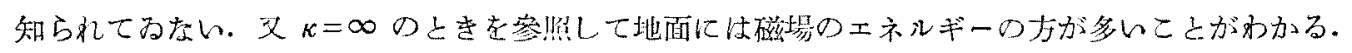

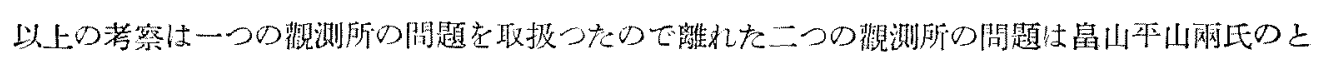

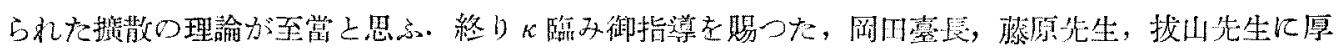
く感謝致します.

\title{
東京市內及び郊外に於ける降水の污瀆に就て(第一派 $)^{(2)}$
}

\section{含茂英次郎・影并㴊介}

Chemical Investigation on the Precipitations at Tokio and its Suburbs.

By H. Kurasige and G. KaGEI

\begin{abstract}
The chemical analyses of the rain water were made through a year of 1934 at four stations in Tôkio and its suburbs. At the Central Meteorological Observatory situated in the central port of Tokio, the rain-water is remarkably soiled by a large quantity of ammonium etc., especially in the daytime. At the both places, Narimune and Ogikubo situating in the suburbs of eity of Tôkio, the quantity of ammonium and nitrate is greatly decreased and the difference between the amounts of daytime and night is not almost appeared in the observed data.
\end{abstract}

\section{I. 緒言}

都會の空氟の活濁の程度を示寸指示物の一つとして降水の硫酸, 䍃素化合物等の化學成分を测定し

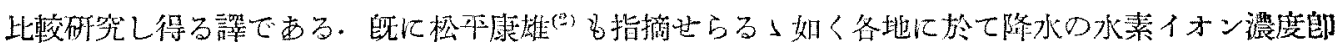
占 Acidity 在测定する事は氣象化學の見地よりる望ましい事で亩るが後述する如く此等化學成分

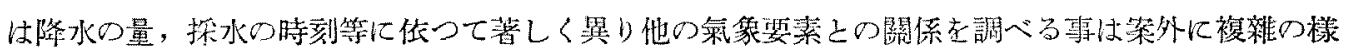
である、本報ては主よして 1934 年中に東宗に於て觀测した降水成分の時間的變化に就て述べる.

著者の一人倉茂は既に別文(

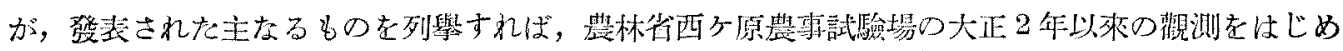

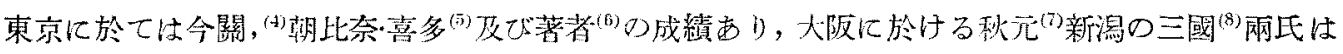

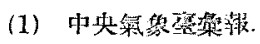

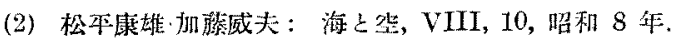

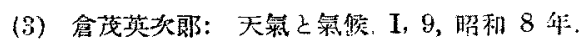

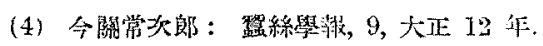

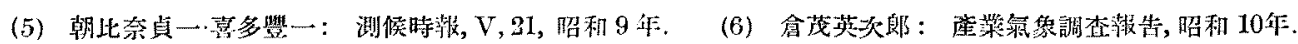

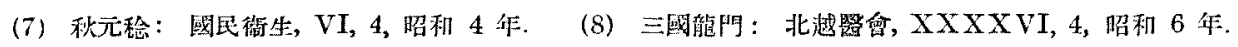

